\title{
Unusual multisystemic involvement and a novel BAG3 mutation revealed by NGS screening in a large cohort of myofibrillar myopathies
}

Anna-Lena Semmler ${ }^{1,2}$, Sabrina Sacconi ${ }^{3}$, J Elisa Bach ${ }^{4}$, Claus Liebe ${ }^{1,2}$, Jan Bürmann ${ }^{5}$, Rudolf A Kley ${ }^{6}$, Andreas Ferbert ${ }^{7}$, Roland Anderheiden ${ }^{8}$, Peter Van den Bergh ${ }^{9}$, Jean-Jacques Martin ${ }^{10}$, Peter De Jonghe ${ }^{10,11,12}$, Eva Neuen-Jacob ${ }^{13}$, Oliver Müller ${ }^{14,15}$, Marcus Deschauer ${ }^{16}$, Markus Bergmann ${ }^{17}$, J Michael Schröder ${ }^{2}$, Matthias Vorgerd ${ }^{6}$, Jörg B Schulz ${ }^{1,18}$, Joachim Weis ${ }^{2,18}$, Wolfram Kress ${ }^{4}$ and Kristl G Claeys $s^{1,2,18^{*}}$

\begin{abstract}
Background: Myofibrillar myopathies (MFM) are a group of phenotypically and genetically heterogeneous neuromuscular disorders, which are characterized by protein aggregations in muscle fibres and can be associated with multisystemic involvement.

Methods: We screened a large cohort of 38 index patients with MFM for mutations in the nine thus far known causative genes using Sanger and next generation sequencing (NGS). We studied the clinical and histopathological characteristics in 38 index patients and five additional relatives $(n=43)$ and particularly focused on the associated multisystemic symptoms.
\end{abstract}

Results: We identified 14 heterozygous mutations (diagnostic yield of 37\%), among them the novel p.Pro209Gln mutation in the BAG3 gene, which was associated with onset in adulthood, a mild phenotype and an axonal sensorimotor polyneuropathy, in the absence of giant axons at the nerve biopsy. We revealed several novel clinical phenotypes and unusual multisystemic presentations with previously described mutations: hearing impairment with a FLNC mutation, dysphonia with a mutation in DES and the first patient with a FLNC mutation presenting respiratory insufficiency as the initial symptom. Moreover, we described for the first time respiratory insufficiency occurring in a patient with the p.Gly154Ser mutation in CRYAB. Interestingly, we detected a polyneuropathy in 28\% of the MFM patients, including a BAG3 and a MYOT case, and hearing impairment in 13\%, including one patient with a FLNC mutation and two with mutations in the DES gene. In four index patients with a mutation in one of the MFM genes, typical histological findings were only identified at the ultrastructural level (29\%).

Conclusions: We conclude that extraskeletal symptoms frequently occur in MFM, particularly cardiac and respiratory involvement, polyneuropathy and/or deafness. BAG3 mutations should be considered even in cases with a mild phenotype or an adult onset. We identified a genetic defect in one of the known genes in less than half of the MFM patients, indicating that more causative genes are still to be found. Next generation sequencing techniques should be helpful in achieving this aim.

Keywords: MFM, Next generation sequencing, bcl-2 associated athanogene protein 3, Protein aggregation, Hearing impairment, Polyneuropathy

\footnotetext{
* Correspondence: kclaeys@ukaachen.de

${ }^{1}$ Department of Neurology, RWTH Aachen University, Aachen, Germany

${ }^{2}$ Institute of Neuropathology, RWTH Aachen University, Aachen, Germany

Full list of author information is available at the end of the article
} 


\section{Background}

Myofibrillar myopathies (MFM) are a group of phenotypically and genetically heterogeneous neuromuscular disorders. The morphological hallmark of MFM is the presence of protein aggregations in muscle fibres, a focal myofibrillar disorganisation starting at the Z-disk and an ectopic expression of proteins, such as desmin [1-6].

Muscle biopsies of MFM patients reveal protein aggregates that are dark blue or purple on the modified Gomori trichrome (mGT) and pink on the haematoxylin and eosin (HE) stains. The aggregations are lacking oxidative enzyme activity on the nicotinamide adenine dinucleotide tetrazolium reductase (NADH-TR) stains. Other light microscopic findings in MFM are rimmed and non-rimmed vacuoles and sometimes cytoplasmic bodies. At the ultrastructural level, the combination of Z-disk streaming and distinct types of protein accumulations is characteristic for MFM and can even give hints towards the mutated gene [7].

To date, mutations in nine genes are known to cause MFM: desmin (DES) [8], aB-crystallin (CRYAB) [9], myotilin (MYOT, also TTID) [10], filamin C (FLNC) [11], Z-band alternatively spliced PDZ motif-containing protein (ZASP, also $L D B 3$ ) [12], four and a half LIM domain protein 1 (FHL1) [13], bcl-2 associated athanogene protein 3 (BAG3) [14], dnaJ homolog subfamily B member 6 (DNAJB6) [15] and titin (TTN) [16]. Mutations in exon 343 of the A-band region of TTN were discovered to cause MFM only very recently [16]. Inheritance in MFM is autosomal dominant in most patients, autosomal recessive in rare cases and X-linked in patients with mutations in FHL1. A broad inter- and intrafamilial variability of phenotypes can be seen in MFM. The age at onset of MFM depends on the underlying gene, mutation and inheritance pattern, but usually the disease starts in adulthood $[17,18]$. Nevertheless also childhood onsets have been described [8,13,14,19-21]. The initial symptom in MFM most frequently is skeletal muscle weakness, other muscular symptoms such as atrophy, hypertrophy, muscle rigidity, contractures, pain or cramps can be present [13,22-26]. Also, the respiratory muscles can be affected in MFM, resulting in a restrictive respiratory insufficiency, which has been reported for most MFM subtypes [4,8,11,14,27-31].

Furthermore, MFM can be associated with distinct multisystemic symptoms, the most frequent being cardiac involvement, ranging from conduction defects and arrhythmias to cardiomyopathies and sudden cardiac death $[4,9,15,26,29,30,32-38]$. The smooth muscles can also be affected in MFM, presenting as chronic diarrhoea or enteric hypomotility [37,39-42], or contributing to bulbar symptoms like swallowing difficulties [27,28,31,33,37,43-45]. Further symptoms associated with MFM exceed the muscles, such as polyneuropathy (PNP) $[10-12,14,46]$, cataracts $[9,31,33]$, gynaecomastia $[29,47]$, and hearing impairment $[39,40,48,49]$.

Serum creatine kinase levels (CK) in MFM patients are normal or only slightly elevated. Electromyography (EMG) reveals myopathic or mixed patterns, but also (pseudo-) myotonic discharges can appear [17,50]. Magnetic resonance imaging (MRI) of the muscles plays an increasing role in the differential diagnosis of muscular disorders and of MFM in particular [51,52].

In the present study, we screened a large cohort of 38 unrelated index patients with MFM for mutations in the nine causative genes, employing next generation sequencing (NGS) and traditional Sanger sequencing. We identified a mutation in 14 index patients, including one novel BAG3 mutation. We performed a detailed clinicopathological characterisation in the index patients and five affected relatives and particularly focused on the associated multisystemic symptoms. We highlight new phenotypical findings in MFM and correlate our data with the literature.

\section{Patients and methods \\ Patients}

In this study, we included 43 patients with MFM belonging to 38 unrelated families (Figure 1). We selected the MFM cases from the muscle and nerve biopsy archive at the Institute of Neuropathology, and from the Neuromuscular Clinic at the Department of Neurology, at the RWTH Aachen University Hospital (Aachen, Germany). The biopsy of patient F10.1 was also included in the study of Joshi et al. [53]. Additionally, eight index patients/ biopsies with MFM were provided by referring centres. The study was performed according to the Declaration of Helsinki and was approved by the ethical committee of the RWTH Aachen University. Written informed consent was obtained from all patients.

\section{Clinical and paraclinical evaluation}

In all 43 patients, we performed a detailed neurological examination, including hearing and swallowing tests, and a blood analysis of the creatine kinase (CK) level. Nerve conduction velocity (NCV) and electromyography (EMG) studies, heart (electrocardiogram (ECG), echocardiography, long-term ECG) and lung examinations (spirometry/bodyplethysmography) were performed in the majority of patients. In addition, an ophthalmological exam was undertaken in patients with complaints of ocular involvement. An EMG was done in all patients with an identified gene defect, except for patients F5.II.2 and F14.1, a diagnostic muscle MRI of the lower extremities in four patients (F1.III.1, F2.III.4, F10.1, F12.III.3) and a whole-body muscle MRI in one (F7.III.4) (1.5 Tesla, Philips, Intera, Best - the Netherlands). 


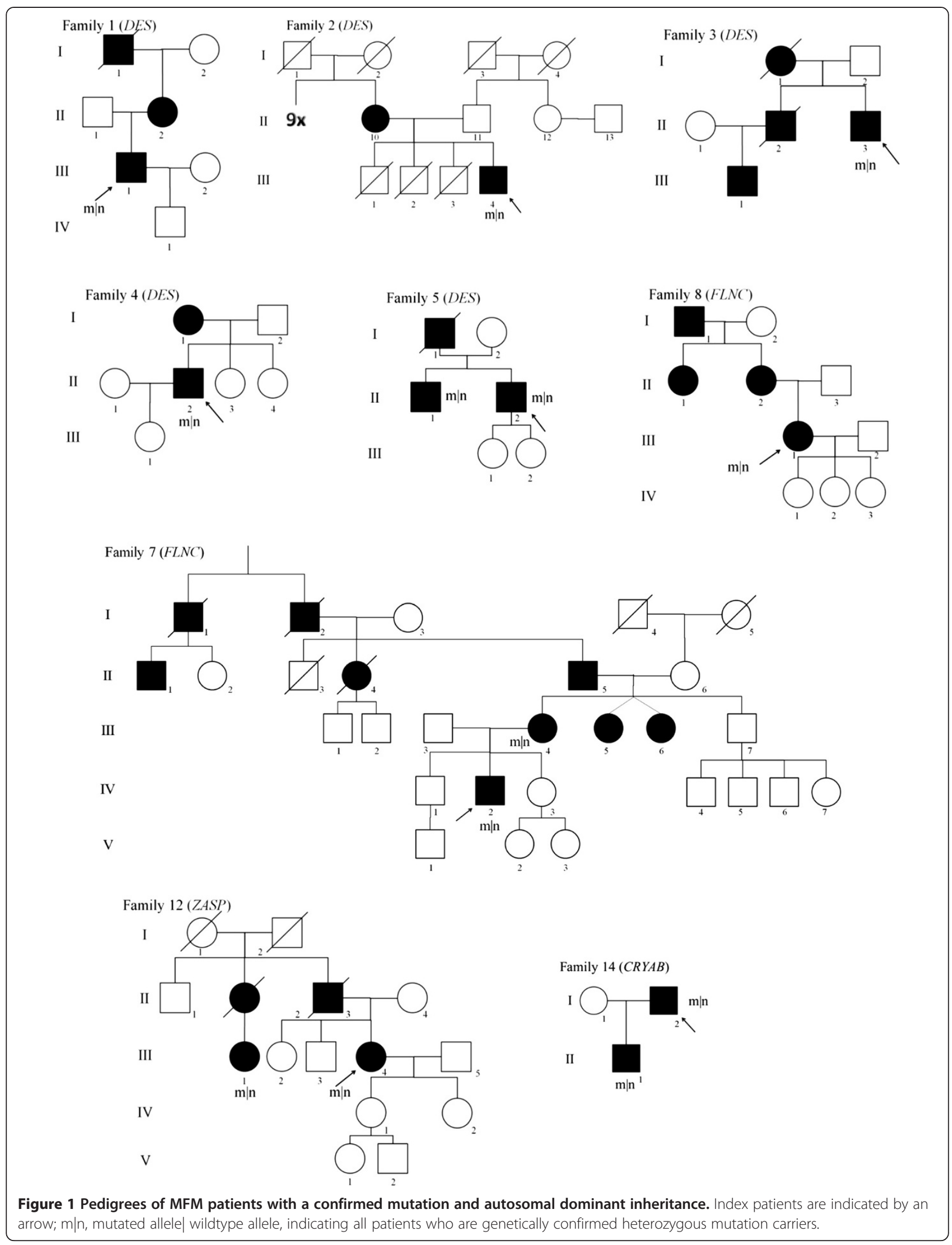




\section{Light microscopy (LM) and electron microscopy (EM) of muscle and nerve biopsies}

Open muscle biopsies had been obtained from the 38 index patients for diagnostic purposes after written informed consent. The muscle tissue sample was divided into unfixed (cryostat), formaldehyde-fixed (paraffin) and glutaraldehyde-fixed (EM) sections and further prepared according to routine protocols. Standard enzyme histochemical and immunohistochemical stains were applied [54]. For electron microscopy (EM) of muscle tissue, which was performed in 31 out of 38 probands, we used a CM10 transmission electron microscope (Philips, Amsterdam, the Netherlands). In addition, seven index patients had simultaneously a diagnostic sural nerve biopsy taken, among them patient F9.1 and F13.1 with a confirmed mutation and a polyneuropathy. The nerve biopsies were processed following standard procedures [55].

\section{Genetic analyses}

Peripheral blood samples and a written informed consent for genetic analysis were available from the 38 index patients, as well as from the affected mother of patient F7.IV.2, the affected brother of patient F5.II.2, the cousin of patient F12.III.4 and the son of patient F14.1. Genomic DNA was extracted using standard procedures. We used two different techniques for genetic analyses in our cohort: Sanger sequencing [56] and next generation sequencing (NGS) [57].

\section{Sanger sequencing of the MFM genes}

We had started screening a group of 21 MFM index patients with conventional Sanger sequencing before the NGS panel for MFM was established. We analysed DES, CRYAB, MYOT (exon 2 and 9), FLNC (exon 48), ZASP (exon 4-10), FHL1, BAG3 and DNAJB6. We performed PCR using standard protocols and used the BigDye Terminator v1.1 mix (Applied Biosystems) for cycle sequencing reactions according to the instructions in the kit. Sequence data were generated with an ABI 3130xl capillary sequencer (Applied Biosystems, Carlsbad, CA, USA) using standard protocols and analysed by GenSearch v.4.0.8 (PhenoSystems, Lillois, Belgium).

\section{NGS panel diagnostics in MFM}

In a NGS approach, the coding exons of all causative genes with the exception of the most recently identified TTN gene were sequenced in the additional 17 index patients included in our study: DES (exon 1-9, NM 001927.3), MYOT (exon 2-10, NM_006790.2), ZASP (exons 5-9 of NM_001080116.1 and exons 4, 7, 8 and 10 of NM_007078.2), FHL1 (exon 3-8, NM_001159702.2), BAG3 (exon 1-4, NM_004281.3), DNAJB6 (exon 2-8,
NM_005494.2), CRYAB (exon 1-3, NM_001885.1) and FLNC (exon 1-48, NM_001458.3). Furthermore, in 10 index patients of our first cohort in which Sanger sequencing was initially performed (see above) and in which no mutations were identified, we subsequently analysed the complete FLNC gene (exon 1-48) applying NGS. Target enrichment was performed with the Access Array System (Fluidigm Corporation, South San Francisco, USA) followed by emulsion PCR and sequence analyses on a GS Junior using kits and instructions by Fluidigm and 454 Life Sciences (Branford, USA). Sequence data were analysed with GenSearch NGS v.1.4 (PhenoSystems, Lillois, Belgium) automatically aligning data to the reference sequences mentioned above. Variants within exons and $20 \mathrm{bp}$ of the flanking intronic sequences were detected with VarScan (http://varscan.sourceforge.net/) using following filters: coverage $>15$, frequency $>20 \%$ for heterozygous or $>75 \%$ for homo- and hemizygous variants. Candidate variants were verified by Sanger sequencing on an ABI 3130xl automated capillary sequencer using standard protocols, and their effect predicted with bioinformatic tools like PolyPhen-2 (http://genetics. bwh.harvard.edu/pph2/index.shtml), SIFT (http://sift.jcvi. org/) and MutationTaster (http://www.mutationtaster.org/) provided by Alamut (Interactive Biosoftware, Rouen, France).

\section{Sanger sequencing of exon 343 of TTN}

Finally, we performed Sanger sequencing to analyse exon 343 of TTN in 25 of our index patients, in whom an underlying gene defect had thus far not been identified (21 patients) or only an unknown variant was revealed (4 patients). PCR, sequencing reaction and data analysis of exon 343 of the TTN gene (NM 001267550.1) have been performed using standard protocols as described above.

\section{Results}

\section{Genetic results in our MFM cohort $(n=43)$ : known and} novel pathogenic mutations

In 14 index patients, we identified a heterozygous pathogenic mutation in one of the nine genes causing MFM (Table 1), corresponding to a diagnostic yield of $37 \%$ in our MFM cohort. In ten patients we found the underlying gene defect using the initial Sanger sequencing study and in four patients by directly employing NGS panel diagnostics. Nine out of the 14 index patients had a positive family history corresponding with an autosomal dominant inheritance (for pedigrees see Figure 1), whereas the others occurred sporadically (Patient F6.1 with a DES mutation, Patient F13.1 with a mutation in $B A G 3$ and all three patients, F9.1, F10.1 and F11.1, with a MYOT mutation, Table 1). We identified six heterozygous mutations in DES, four of these were the Arg350Pro 
Table 1 Clinical characteristics of myofibrillar myopathy patients with an identified mutation

\begin{tabular}{|c|c|c|c|c|c|c|c|c|c|c|c|c|c|c|c|c|c|c|c|c|c|c|}
\hline \multirow[t]{2}{*}{ Pat. } & \multirow[t]{2}{*}{$M / F$} & \multirow[t]{2}{*}{$\mathrm{FH}$} & \multirow[t]{2}{*}{ Gene } & \multirow[t]{2}{*}{ Exon } & \multirow[t]{2}{*}{ Mutation } & \multirow[t]{2}{*}{ AAO } & \multirow[t]{2}{*}{ AAE } & \multirow{2}{*}{$\begin{array}{c}\text { First } \\
\text { symptom }\end{array}$} & \multicolumn{10}{|c|}{ Weakness } & \multicolumn{3}{|c|}{ Multisystemic symptoms } & \multirow[t]{2}{*}{ CK } \\
\hline & & & & & & & & & $\begin{array}{l}\text { UL } \\
\text { prox. }\end{array}$ & $\begin{array}{l}\text { UL } \\
\text { dist. }\end{array}$ & $\begin{array}{l}\text { LL } \\
\text { prox. }\end{array}$ & $\begin{array}{l}\text { LL } \\
\text { dist. }\end{array}$ & ptosis & axial & $\begin{array}{l}\text { scapular } \\
\text { winging }\end{array}$ & $\begin{array}{c}\text { dys- } \\
\text { phagia }\end{array}$ & $\begin{array}{l}\text { dys- } \\
\text { phonia }\end{array}$ & $\begin{array}{c}\text { respiratory } \\
\text { involvement }\end{array}$ & $\begin{array}{c}\text { cardiac } \\
\text { involvement }\end{array}$ & PNP & $\begin{array}{l}\text { hearing } \\
\text { imp. }\end{array}$ & \\
\hline F1.III.1 & M & + & DES & 6 & Arg350Pro & 39 & 47 & weakness LL & + & - & + & + & - & - & - & - & - & - & - & - & - & 1031 \\
\hline F2.III.4 & M & + & DES & 6 & Arg350Pro & 42 & 74 & weakness LL & - & - & + & + & - & + & - & - & - & - & - & - & - & 2690 \\
\hline F3.II.3 & M & + & DES & 6 & Arg350Pro & 48 & 59 & dyspnoea & + & + & + & + & + & - & - & - & - & VC 45\%,NV & $\begin{array}{l}\text { TAA intermittent, } \\
\text { LV hypertrophy }\end{array}$ & - & + & 2044 \\
\hline F4.II.2 & M & + & DES & 6 & Arg350Pro & 36 & 42 & weakness LL & + & - & + & + & - & - & - & + & - & - & - & - & + & 1159 \\
\hline F5.II.2 & M & + & DES & 1 & Ser2lle & 60 & 72 & syncopes & + & - & + & + & - & + & + & - & - & - & $3^{\circ} \mathrm{AVB}, \mathrm{PM}$ & - & - & $\mathrm{nl}$ \\
\hline F6.1 & $\mathrm{F}$ & - & DES & 3 & Glu245Asp & 51 & 62 & weakness LL & - & - & + & + & - & - & - & - & - & - & $\begin{array}{c}\mathrm{DCM}, \mathrm{AF}, 3^{\circ} \mathrm{AVB}, \\
\mathrm{PM}, \mathrm{TI}\end{array}$ & - & - & $\mathrm{nl}$ \\
\hline F7.IV.2 & M & + & FLNC & 18 & $\begin{array}{l}\text { Val930_Thr } \\
\text { 933del }\end{array}$ & 28 & 40 & weakness LL & - & - & + & - & - & - & + & - & - & - & - & - & - & 629 \\
\hline F7.III.4 & $\mathrm{F}$ & + & FLNC & 18 & $\begin{array}{l}\text { Val930_Thr } \\
\text { 933del }\end{array}$ & 53 & 60 & weakness LL & - & - & + & + & - & - & - & - & - & - & - & - & + & 388 \\
\hline F8.III.3 & $\mathrm{F}$ & + & FLNC & 48 & Trp2710X & 53 & 59 & dyspnoea & + & - & + & + & - & - & + & - & - & VC 35\%,NV & - & - & - & 500 \\
\hline F9.1 & M & - & MYOT & 2 & Ser60Phe & 67 & 71 & dyspnoea & - & - & - & + & + & - & - & - & - & - & $\begin{array}{c}\text { LBBB, HF, AF, } \\
3^{\circ} \mathrm{AVB} \text { intermittent, } \\
\text { PM }\end{array}$ & $\mathrm{ad} / \mathrm{sm}$ & - & 206 \\
\hline F10.1 & M & - & MYOT & 2 & Ser60Phe & 63 & 67 & myalgia LL & - & - & + & - & - & - & - & - & - & - & - & - & - & 589 \\
\hline F11.1 & M & - & MYOT & 2 & Ser55Phe & 55 & 60 & weakness LL & + & - & + & + & - & - & - & - & - & mild & $\begin{array}{c}A F, P M, I C D, D C M \\
H T x\end{array}$ & - & - & 608 \\
\hline F12.III.3 & $\mathrm{F}$ & + & ZASP & 6 & Ala165Val & 46 & 57 & $\begin{array}{l}\text { walking } \\
\text { difficulties }\end{array}$ & - & + & - & - & - & - & - & - & - & - & - & - & - & 182 \\
\hline F13.1 & M & - & $B A G 3$ & 3 & Pro209GIn & 34 & 43 & weakness LL & + & & + & + & & & + & & - & - & - & $\mathrm{a} / \mathrm{sm}$ & - & 1050 \\
\hline F14.1 & M & + & CRYAB & 3 & Gly154Ser & 69 & 69 & rhabdomyolysis & - & - & - & - & - & - & - & - & - & VC 65\% & - & - & - & 2000 \\
\hline
\end{tabular}

$\mathrm{M} / \mathrm{F}$, male/female; $\mathrm{FH}$, family history; $\mathrm{AAO}$, age at onset; $\mathrm{AAE}$, age at examination; $\mathrm{CK}$, level of creatine kinase in serum in $\mathrm{U} / \mathrm{L}$ (normal value $<174)$; $\mathrm{UL}$, upper limb; $\mathrm{LL}$, lower limb; prox., proximal; dist., distal; PNP, polyneuropathy; Hearing imp., hearing impairment; VC, vital capacity; NC, nocturnal ventilation; TAA, tachyarrhythmia absoluta; LV, left ventricle; $3^{\circ} \mathrm{AVB}$, complete atrioventricular conduction block; nl, normal; DCM, dilated cardiomyopathy; AF, atrial fibrillation; PM, pace maker; Tl, tricuspid insufficiency; LBBB, left bundle branch block; HF, heart failure; ad/sm, axonal demyelinating/sensorimotor; ICD, implantable cardioverter defibrillator; $\mathrm{HTx}$, heart transplantation; a/sm, axonal/sensorimotor; for abbreviations of genes see text. 
mutation, two different mutations in FLNC, and three MYOT mutations, including two times the Ser60Phe mutation in exon 2. One mutation each was found in ZASP, $C R Y A B$ and in $B A G 3$ (Table 1, Figure 1). The mutation in $B A G 3$ represents a novel mutation, whereas the other mutations have been described previously.

The c.626C > A, p.Pro209Gln mutation in exon 3 of BAG3 (Patient F13.1, Table 1) is so far not known in the databases of the NHLBI exome sequencing project (ESP) or the 1000 genome project and was predicted to be disease causing by all used prediction programmes. Further arguments for pathogenicity came from familial segregation analysis, in which both healthy parents did not harbour the mutation, indicating a de novo mutation.

\section{Genetic results in our MFM cohort $(n=43)$ : polymorphisms and unclassified variants}

With means of NGS panel diagnostics we found a large number of variants, especially in FLNC. The suspicious variants with a minor allele frequency beneath $1 \%$ are listed in Additional file 1. We assessed these variants with various databases and prediction programmes. Especially the pathogenicity of the c.6595G > A, p.Gly2199Arg mutation in exon 40 of FLNC (patient F20.1, Additional file 1) finally remained unclear. This genetic variant has only been counted once by the NHLBI exome sequencing project (ESP) and was predicted to be benign by PolyPhen-2, but disease causing by Mutation Taster. The glycin residue at position c.6595 is highly conserved, as well as the nucleotide at this position. Unfixed muscle tissue of this patient was not available anymore and no new muscle biopsy could be obtained, so that additional proteomic analyses for possible further clarification could not be performed. Moreover, family members were not available for segregation analysis to further clarify the pathogenicity.

\section{Clinical findings in MFM patients with an identified gene defect $(n=14)$}

The 14 index patients with an identified mutation included eleven males and three females (Table 1). The age at onset ranged from 28 to 69 years (mean 49 years). The most common initial symptom was weakness in the legs (64\%). In three patients the first symptom was dyspnoea (21\%) and in one syncopes (7\%), indicating a respiratory or cardiac onset of the disease. At the time of examination, the disease persisted already up to 32 years (mean disease duration 9 years). Muscle weakness was distributed in the distal and proximal lower limbs, combined with weakness in the proximal upper limbs in six of the 14 patients. Patients F3.II.3 and F6.1 were wheelchair bound since the age of 59 and 60 years respectively, both after 11 years of disease progression. Scapular winging was evident in $29 \%$ of the patients, $14 \%$ showed additional axial weakness and $14 \%$ a ptosis without ophthalmoparesis or facial weakness (Table 1). In $64 \%$ of the patients, atrophy of the distal lower limbs was present, among them the two patients with an additional PNP. EMG revealed a myopathic pattern in $58 \%$ and a mixed pattern in $42 \%$, in three of the patients with a mixed pattern also pseudomyotonic discharges were present. The serum CK levels varied from normal to 16 fold elevated (mean: $5.5 \mathrm{~N}$ ) (Table 1). Only patient F14.1 did not show permanent skeletal muscle weakness.

\section{Multisystemic symptoms in the whole MFM cohort ( $n=43)$}

In general, $16 \%$ of the patients included in the study $(n=43)$ had respiratory involvement and $60 \%$ presented one or more multisystemic symptom(s) (Table 2). The most striking finding was the large number of MFM patients with mainly a sensorimotor axonal-demyelinating polyneuropathy (12/43 or $28 \%)$, which occurred as frequently as cardiac disease (Table 2). In $50 \%(n=6)$ of the MFM patients with a polyneuropathy, no other possible cause was present. However, another $33 \%(n=4)$ suffered from diabetes mellitus and $17 \%(n=2)$ had taken neurotoxic medications, as possible (additional) causes of a polyneuropathy. The PNP was diagnosed after 0-6 years of disease duration (mean: 1.7 years). 14\% of the MFM patients suffered from hearing impairment, with a symptom onset between 16 and 80 years of age. Half of these patients used hearing devices. We did not detect diarrhoea, intestinal malabsorption or pseudoobstruction in our cohort.

\section{Multisystemic symptoms in MFM patients with an identified mutation ( $n=14$ and affected relatives)}

In the group of index patients with a pathogenic mutation $(n=14) 64 \%$ showed at least one multisystemic symptom (Figure 1, Tables 1 and 2). Patient F3.II.3 harbours the Arg350Pro mutation in DES and presented with exertional dyspnoea as initial symptom at 48 years of age. Subsequently, he developed dyspnoea at rest, had a vital capacity (VC) of $45 \%$ of the theoretical value and needed non-invasive continuous positive airway pressure (CPAP) ventilation at night. Furthermore, he presented an intermittent tachyarrhythmia absoluta and a hypertrophic left ventricle at echocardiography. He also suffered from bilateral hypacusis and used a hearing aid on the right side since the age of 52 years.

Patient F4.II.2 carried the same Arg350Pro mutation in $D E S$ and recognised swallowing problems after six years of disease progression. He also presented a bilateral hypacusis since the age of 38 years.

Only the affected mothers of two more patients with the Arg350Pro mutation in DES (patient F1.III.1; F2.III.4) showed multisystemic symptoms (respiratory insufficiency, 
Table 2 Multisystemic symptoms of all included MFM patients $(n=43)$

\begin{tabular}{|c|c|c|c|}
\hline \multicolumn{2}{|l|}{ Symptom } & \multicolumn{2}{|c|}{ Frequency } \\
\hline Respiratory symptoms (6) & restricted vital capacity & $6^{* *}$ & $(1 \times D E S, 1 \times F L N C, 1 \times M Y O T, 1 \times C R Y A B)$ \\
\hline & ventilation assistance & 1 & \\
\hline & nocturnal ventilation & 2 & $(1 \times D E S, 1 \times F L N C)$ \\
\hline \multirow[t]{18}{*}{ Cardiac symptoms (12) } & atrial fibrillation & 8 & $(1 \times D E S, 2 \times M Y O T)$ \\
\hline & tachyarrhythmia absoluta & 1 & $(1 \times D E S)$ \\
\hline & ventricular tachycardia & 1 & \\
\hline & bradycardia & 1 & \\
\hline & ventricular extrasystoles & 1 & \\
\hline & $3^{\circ} \mathrm{AV}$ block & $3^{*}$ & $(2 \times D E S, 1 \times M Y O T)$ \\
\hline & LBBB & 2 & $(1 \times$ MYOT $)$ \\
\hline & RBBB & 1 & \\
\hline & bifascicular block & 1 & \\
\hline & tricuspid insufficiency & 2 & $(1 \times D E S)$ \\
\hline & aortic/mitral/tricuspid insufficiency & 1 & \\
\hline & heart failure & 3 & $(1 \times$ MYOT $)$ \\
\hline & LV hypertrophy & 3 & \\
\hline & DCM & 2 & $(1 \times D E S, 1 \times M Y O T)$ \\
\hline & pace maker & 6 & $(2 \times D E S, 2 \times M Y O T)$ \\
\hline & ICD & 1 & $(1 \times$ MYOT) \\
\hline & heart transplantation & 1 & $(1 \times M Y O T)$ \\
\hline & sudden cardiac death & 0 & \\
\hline \multirow[t]{7}{*}{ Polyneuropathy (12) } & axonal & 3 & $(1 \times B A G 3)$ \\
\hline & demyelinating & 0 & \\
\hline & axonal-demyelinating & 9 & $(1 \times$ MYOT) \\
\hline & sensory & 0 & \\
\hline & sensory + autonomic & 1 & \\
\hline & motor & 1 & \\
\hline & sensorimotor & 10 & $(1 \times M Y O T, 1 \times B A G 3)$ \\
\hline \multirow[t]{2}{*}{ Bulbar symptoms (8) } & dysphagia & 5 & $(1 \times D E S)$ \\
\hline & dysphonia & 2 & $(1 \times D E S)$ \\
\hline Hearing impairment & & 6 & $(2 \times D E S, 1 \times F L N C)$ \\
\hline Gynaecomastia & & 1 & \\
\hline
\end{tabular}

One patient can present more than one multisystemic symptom; between brackets, the number of cases with an identified mutation in whom the symptom was present; ${ }^{* *}$, symptom was the onset symptom in two cases; $3^{\circ} \mathrm{AV}$ block, complete atrioventricular conduction block; ${ }^{*}$, symptom was the onset symptom in one case; LBBB, left bundle branch block; RBBB, right bundle branch block; LV, left ventricle; DCM, dilated cardiomyopathy; ICD, implantable cardioverter defibrillator

cardiac involvement with a pace maker implantation, polyneuropathy).

Patient F6.1 carried the Glu245Asp mutation in DES and exhibited cardiac symptoms: a dilated cardiomyopathy was diagnosed approximately ten years after disease onset and a chronic atrial fibrillation and complete atrioventricular block occurred, necessitating pace maker implantation.

The patient carrying the Ser2Ile mutation in DES (patient F5.II.2) presented with syncopes as the first symptom at the age of 60 years, due to a complete atrioventricular conduction block leading to pace maker implantation. At the age of 65 years, he developed mild distal lower leg weakness and dysphonia. Other causes of dysphonia were excluded. Interestingly, the patient's father also had dysphonia and a pacemaker implantation at the age of 58 years. The patient's brother, carrying the same mutation, received a pacemaker at the age of 45 years and had mild distal involvement of the lower legs, but no dysphonia.

Patient F8.III.3 with the Trp2710X mutation in FLNC developed respiratory problems three years before 
weakness in the extremities occurred. After five years of disease progression, the patient was dependent on noninvasive nocturnal ventilation. VC decreased to $35 \%$.

The affected mother of the index patient harbouring the Val930_Thr933del mutation in FLNC (patient F7.III.4) presented with bilateral hearing impairment and hearing aids at the age of 60 years.

Patient F9.1 carrying the Ser60Phe mutation in MYOT developed exertional dyspnoea due to heart failure at the age of 64 years as the first symptom. A left bundle branch block, an intermittent atrioventricular conduction block and atrial fibrillation were diagnosed, and a pace maker was implanted. The patient also suffered from coronary disease. Four years later, a sensorimotor axonal-demyelinating polyneuropathy was diagnosed.

In Patient F11.1 with a Ser55Phe mutation in MYOT, cardiac symptoms began shortly after skeletal weakness became apparent at the age of 55 years. He had a permanent atrial fibrillation with tachyarrhythmia absoluta and received an implantable cardioverter defibrillator (ICD). In addition, he had several myocardial infarctions due to coronary disease. One year later, a dilated cardiomyopathy was diagnosed and heart transplantation was performed.

Patient F14.1 carries the p.Gly154Ser mutation in $C R Y A B$ and presented at the age of 69 years with several episodes of rhabdomyolysis. The patient also complained about exercise intolerance and fatigue. The neurological examination was normal, but a respiratory involvement with a $\mathrm{VC}$ of $65 \%$ in lying position was diagnosed. His 42-year-old son, carrying the same mutation, was asymptomatic and only showed a moderate serum CK elevation.

MRI findings in MFM patients with an identified mutation Muscle MRI findings are summarised and compared to the literature in Table 3.

\section{Histological findings of the MFM cohort}

In the 14 index patients with an identified mutation we consistently found an increased variability of fibre diameter (100\%), frequent nuclear bags (64\%), internal nuclei (86\%), vacuoles (64\%), rimmed vacuoles (50\%) and

Table 3 MRI findings in five MFM patients with an identified mutation

\begin{tabular}{|c|c|c|c|c|c|c|c|c|c|}
\hline \multirow{3}{*}{$\begin{array}{l}\text { Gene } \\
\text { Patient }\end{array}$} & \multicolumn{4}{|c|}{ Fischer et al. 2008} & \multicolumn{5}{|c|}{ Current study } \\
\hline & \multirow[t]{2}{*}{$D E S$} & \multirow[t]{2}{*}{ FLNC } & \multirow[t]{2}{*}{ MYOT } & \multirow[t]{2}{*}{$Z A S P^{*}$} & \multicolumn{2}{|c|}{$D E S$} & \multirow{2}{*}{$\begin{array}{c}\text { FLNC } \\
\text { F7.III.4 }\end{array}$} & \multirow{2}{*}{$\begin{array}{l}\text { MYOT } \\
\text { F10.1 }\end{array}$} & \multirow{2}{*}{$\begin{array}{r}\text { ZASP } \\
\text { F12.III.3 }\end{array}$} \\
\hline & & & & & F1.III.1 & F2.III.4 & & & \\
\hline \multicolumn{10}{|l|}{ Pelvic level } \\
\hline Gluteus maximus & 2,3 & 1,3 & 2 & 3 & 3 & $\mathrm{np}$ & 1 & $\mathrm{np}$ & $\mathrm{np}$ \\
\hline Gluteus medius & 1,8 & 1,7 & 2,8 & 1 & 1 & $\mathrm{np}$ & 1 & $\mathrm{np}$ & $\mathrm{np}$ \\
\hline Gluteus minimus & 1,8 & 1,7 & 3,3 & 3 & 3 & $\mathrm{np}$ & 1 & $\mathrm{np}$ & $\mathrm{np}$ \\
\hline \multicolumn{10}{|l|}{ Mid thigh level } \\
\hline Vastus lateralis & 1,2 & 1,2 & 1,6 & 2 & 3 & 1 & 2 & 1 & 1 \\
\hline Vastus intermedius & 1,2 & 2,8 & 2,8 & 3 & 4 & 1 & 3 & 1 & 1 \\
\hline Vastus medialis & 1,3 & 2,3 & 2,8 & 3 & 4 & 1 & 3 & 1 & 1 \\
\hline Rectus femoris & 1,3 & 0,4 & 0,1 & 2 & 1 & 1 & 2 & 1 & 1 \\
\hline Sartorius & 2,8 & 0,7 & 1,5 & 1 & 4 & 3 & 1 & 2 & 1 \\
\hline Gracilis & 2,2 & 0,6 & 0,4 & 1 & 3 & 3 & 1 & 1 & 1 \\
\hline Biceps femoris & 1,5 & 3,3 & 2,9 & 4 & 1 & 1 & 3 & 3 & 3 \\
\hline Adductor magnus & 1,7 & 3,2 & 3,2 & 4 & 3 & 1 & 3 & 3 & 2 \\
\hline Semitendinosus & 3,1 & 1,8 & 1,2 & 3 & 3 & 3 & 3 & 2 & 1 \\
\hline Semimembranosus & 1,5 & 3,3 & 2,8 & 4 & 2 & 1 & 3 & 2 & 3 \\
\hline \multicolumn{10}{|l|}{ Mid leg level } \\
\hline Tibialis anterior & 1,9 & 2,8 & 3,1 & 3 & 3 & 2 & 0 & 1 & 3 \\
\hline Peroneal muscle group & 3 & 2,7 & 2,8 & 3 & 2 & 4 & 1 & 1 & 2 \\
\hline Medial gastrocnemius & 2 & 3 & 3,4 & 3 & 2 & 3 & 3 & 4 & 4 \\
\hline Lateral gastrocnemius & 2,1 & 0,9 & 2,1 & 3 & 2 & 3 & 1 & 3 & 4 \\
\hline Soleus & 2,2 & 3,6 & 3,9 & 4 & 4 & 2 & 3 & 3 & 4 \\
\hline
\end{tabular}

5-point scale according to Fischer et al. 2008 [51]: stage 0 is referred to a normal muscle appearance; stage 1 means traces of increased signal intensity on the T1-weighted MR sequences; stage 2 refers to increased signal intensity on MRI in less than $50 \%$ of the muscle; stage 3 means an increased signal intensity on MRI in more than $50 \%$ of the muscle; stage 4 indicates an increased signal intensity on MRI in the entire muscle (end-stage disease); ${ }^{*}, Z A S P$ classification is based on Figure four in the study of Fischer et al. 2008; np, not performed; for abbreviations of genes see text. 
increased endomysial connective tissue (79\%). In $43 \%$ of the biopsies, cytoplasmic bodies and core-like lesions on the NADH-TR staining were revealed. Myofibrillar disorganisation was seen in all cases, but characteristic protein aggregations in the cytoplasm of mGT stained fibres were found in only 10 of the 14 cases (71\%) (Patient F11.1: in the vastus medialis muscle biopsy protein aggregations were seen, but not in the simultaneously obtained tibialis anterior muscle biopsy). So $29 \%$ only showed typical MFM findings at the ultrastructural level (EM was performed in 11 of the 14 cases). Z-disk streaming and myofibrillar disorganisation were seen in 100\%, granulofilamentous material in 64\%. Abnormal mitochondria (64\%), tubulofilamentous accumulations (29\%) and cytoplasmic bodies (36\%) were other frequent findings. Immunhistochemistry with antibodies directed against desmin showed immunoreactivity in all 8 performed cases.

In the group of 24 patients, in whom the underlying genetic defect had not been identified, we made similar observations. Characteristic protein aggregations in the cytoplasm of mGT stained fibres were found in $76 \%$ of the cases, myofibrillar disorganisation in $82 \%$.

In ten of the 12 MFM patients additionally presenting a polyneuropathy, we observed neurogenic muscle atrophy, which found expression in angular shaped muscle fibres and fibre type grouping.

\section{Clinicopathological phenotype of the patient with a novel BAG3 mutation}

Patient F13.1 harbours the novel Pro209Gln mutation in BAG3 (Table 1). He presented first symptoms of distal lower limb weakness and symmetrical calve atrophy at the age of 34 years. The skeletal muscle weakness spread to the proximal lower limbs and finally to the proximal upper limbs with scapular winging after 2 more years of disease progression. Moreover, he developed an axonal sensorimotor polyneuropathy, as multisystemic symptom of MFM. No other obvious cause for the PNP could be found. The PNP was first diagnosed at the age of 39 years and finds expression in decreased vibration sense and ataxic, clumsy gait as well as an increased sensitivity for cold. EMG showed a mixed pattern and the maximum CK level was $1050 \mathrm{U} / \mathrm{L}$ (Table 1). The muscle biopsy showed desmin positive protein deposits, vacuoles and core-like lesions as well as some necrotic fibres. At the ultrastructural level, tubulofilamentous accumulations, lobulated nuclei and glycogen accumulations were seen, in addition to typical MFM findings like Z-disk streaming and the accumulation of granulofilamentous material. We did not observe regenerating fibres or apoptotic nuclei. The ultrastructural study of nerve tissue revealed no giant axons.

\section{Discussion}

In a large cohort of MFM patients, we identified heterozygous mutations in 14 of 38 index patients (diagnostic yield of 37\%), including the novel p.Pro209Gln mutation in exon 3 of $B A G 3$, using Sanger and next generation sequencing (NGS) of the nine thus far known causative genes of MFM. Furthermore, we discovered new phenotypes associated with previously described mutations, such as hearing impairment with a FLNC mutation, dysphonia with a mutation in $D E S$ and the first patient with a FLNC mutation presenting respiratory insufficiency as the onset symptom. Interestingly, we detected a polyneuropathy in more than a quarter of the MFM patients, including a BAG3 and a MYOT case (Figure 2).

\section{Methodological issue: Sanger versus NGS sequencing}

In ten of our patients, a mutation in one of the MFMcausative genes was identified using conventional Sanger sequencing. By employing NGS, we additionally found four mutations, among them the novel BAG3 mutation, as well as a lot of variants, especially in FLNC, beyond the mutational hotspot in exon 48. The mass of variants that are found using NGS and their sometimes difficult interpretation can currently still be considered as a drawback of this technique. However, knowledge concerning the variants will increase in the following years as NGS will become more widely available and databases more complete. Advantages of NGS are reduced costs and decreased time to diagnosis. Furthermore, a specific and often unreliable genetic testing sequence is made redundant, especially in diseases with overlapping morphological and/or clinical phenotypes, such as MFM. The difficulty in interpretation of certain variants is illustrated by the unknown variant p.Gly2199Arg in exon 40 of FLNC of patient F20.1 (Additional file 1).

\section{Novel mutation identified in BAG3 and associated phenotype}

The novel BAG3 mutation is located at the amino acid position p.209 and proline is replaced by glutamine. At the same position the p.Pro209Leu mutation is situated, which is the most common BAG3 mutation associated with MFM [14,36,46,48]. In all previously described MFM cases with the p.Pro209Leu mutation, the disease started within the first or second decade and was hallmarked by rapidly progressive muscle weakness, severe cardiac and respiratory involvement and early death of the patients in some cases. In nine of the eleven reported cases an axonal polyneuropathy was additionally found. Our patient's (Patient F13.1, Table 1) mild phenotype with adultonset skeletal muscle weakness and the absence of cardiac or respiratory involvement clearly differs from the other BAG3-associated MFM cases, solely his axonal sensorimotor PNP is in concordance. Only one other 


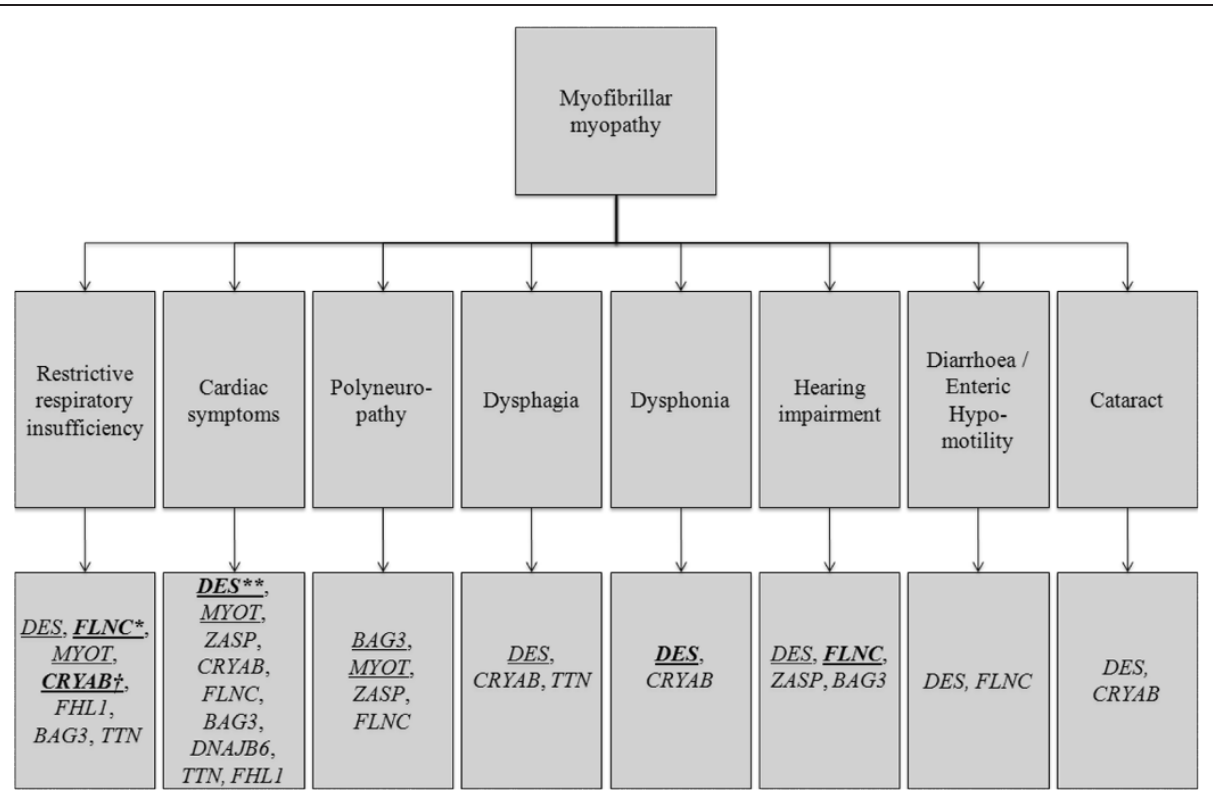

Figure 2 Flowchart of multisystemic symptoms of MFM. Underlined, findings in current study; bold, new findings in current study; ${ }^{*}$, for the first time described as onset symptom with FLNC mutation in current study; ${ }^{* *}$, for the first time described as onset symptom with p.Ser2lle DES mutation in current study; $\uparrow$ for the first time described with p.Gly154Ser CRYAB mutation in our study; not underlined, literature findings.

adult-onset patient with $B A G 3$-related MFM has thus far been described: a woman harbouring the p.261-265 RAASP deletion in $B A G 3$, who showed involvement of the orbicularis oculi muscles and the lower limb muscles, as well as photophobia and diplopia, starting at the age of 60 years. Her muscle biopsy revealed typical MFM findings [58].

In our patient's nerve and muscle biopsy no giant axons could be found, which were described before in BAG3-associated MFM cases [36,46,48]. Muscle biopsy findings were typical for MFM. We observed some lobulated nuclei at electron microscopy, corresponding to the findings of Selcen et al. who also described abnormal nuclei up to apoptotic changes in one MFM patient with a $B A G 3$ mutation [14].

\section{Multisystemic symptoms in MFM, unusual phenotypes}

We identified new phenotypes considering the multisystemic symptoms of our patients in association with certain mutations in the MFM genes (Figure 2; for review of the literature see Additional file 2). We reported hearing impairment for the first time in patients with the p.Arg350Pro DES mutation and for the first time in combination with a FLNC mutation (p.Val930_Thr933del). Also three other patients of our cohort (Table 2) presented with hearing problems, in one case (unidentified gene defect) the complaints began at the age of 16 years. Hearing impairment as a multisystemic symptom of MFM was described by Kraya et al. in two patients with a ZASP mutation, in a patient harbouring an unknown variant in $B A G 3$ and in one autosomal recessive $D E S$ case, as a congenital feature $[39,40,48,49]$.

We moreover present two new onset symptoms: syncopes due to a conduction block associated with the p.Ser2Ile mutation in DES and dyspnoea due to respiratory insufficiency for the first time with a FLNC mutation. In the patient with the DES mutation mild skeletal muscle involvement appeared only after several years. The two reported cases with the same mutation both showed skeletal muscle involvement at baseline [59], so this is the first described pure cardiac onset case associated with this mutation. Moreover dysphonia was noted in the propositus and his father. So far, only dysphagia and nasal voice have been described with DES mutations [27], dysphonia has only been described with CRYAB mutations [31].

Respiratory insufficiency has been described in association with the p.Trp2710X mutation in FLNC, and frequently was the cause of death, but never the initial symptom $[11,30,60]$. It was not reported as an initial symptom in patients with other FLNC mutations, either. Also in patient F14.1 respiratory involvement was diagnosed, which has not been reported before with the p.Gly154Ser mutation in CRYAB $[47,61]$.

The high frequency of polyneuropathy in our MFM cohort was striking (Table 2). We found PNP in combination with a novel BAG3 and a known MYOT (p.Ser60Phe) mutation (Table 1). Both, BAG3 and MYOT mutations, have been reported in MFM patients who also presented a PNP $[10,14,46]$. Nine additional index patients 
of our cohort showed evidence for a polyneuropathy, but no mutation was found in these cases. Thus, there probably are other genes which cause a combined phenotype of MFM and polyneuropathy.

The most common cardiac symptoms in our cohort were arrhythmias (83\%), followed by conduction defects (50\%). This is in accordance with a 10-year longitudinal study in DES patients, in which conduction defects were the most common cardiac manifestation [59].

Taking the whole cohort into account, five patients complained about swallowing problems (one carried a $D E S$ p.Arg350Pro mutation).

The occurrence of multisystemic symptoms might be explained by the expression profiles of the proteins encoded by the MFM genes. However, the expression of proteins remains partially unknown, e.g. FLNC expression in the vestibulocochlear nerve.

\section{Muscle MRI findings compared to the literature}

For detailed values of the different muscles compared to the literature see Table 3 [51]. Patient F1.III.1 and patient F2.III.4 harbour the same mutation in DES (Table 1, Figure 1). Patient F2.III.4 showed an equal pattern of muscle involvement as described before even after 32 years of disease duration. However, the pattern seen in patient F1.III.1 is different, especially his gluteus minimus, quadriceps, and soleus muscle were far more involved than in previously reported cases. Patient F7.III.4 carries a FLNC mutation and showed a relatively typical pattern of muscle involvement in the MRI, only the severe involvement of the rectus femoris and semitendinosus and the spared tibialis anterior muscle was rather unusual. In the patient with a MYOT mutation (patient F10.1) we would have expected the involvement of the tibialis anterior muscle, because of the severely involved posterior compartment, as well as the vastus medialis and intermedius muscles which are described to be one of the most affected in the literature and are only mildly involved here. In the patient with a ZASP mutation (patient F.12.III.3) we found a rather mild involvement at muscle MRI, but as was described before biceps femoris and semimembranosus muscles were most severely affected.

\section{Conclusion}

We conclude that multisystemic involvement frequently occurs in MFM. Most important are the cardiac and respiratory symptoms, but also polyneuropathies, hearing loss and bulbar symptoms can occur. BAG3 should be included in the genetic workup of MFM patients, even in cases with an adult onset and a mild phenotype. In $29 \%$ of all biopsies no aggregations were found at the light microscopic level, however, typical ultrastructural findings were present, underlining the importance of electron microscopy in the diagnosis of MFM. In contrast, $76 \%$ of the patients/biopsies without a genetic identification showed distinct protein deposits in the cytoplasm of the muscle cells. This high rate and our percentage of identified mutations (37\%) lead to the conclusion that more causative genes for MFM are still to be found. NGS might be helpful in achieving this aim.

\section{Additional files}

Additional file 1: Non-pathogenic or unclassified variants identified by means of NGS panel diagnostics in the MFM-causing genes. Additional file 2: Review of multisystemic symptoms described in literature.

\section{Competing interests}

The authors declare that they have no conflicts of interest.

\section{Authors' contributions}

AS carried out the acquisition and interpretation of clinical, histopathological and imaging data, participated in the molecular genetic and

histopathological studies and drafted the manuscript. SS was involved in collecting and analysing clinical and histopathological data and revised the manuscript. JEB carried out molecular genetic studies and drafted parts of the manuscript. CL participated in acquisition and interpretation of clinical and histopathological data and revised the manuscript. JB was involved in collecting and analysing clinical data and revised the manuscript. RAK was involved in collecting and analysing clinical data and revised the manuscript. AF participated in collecting and analysing clinical and imaging data and revised the manuscript. RA was involved in collecting and analysing clinical data and revised the manuscript. PVdB was involved in collecting and analysing clinical and histopathological data and revised the manuscript. JJM participated in the acquisition and interpretation of clinical and histopathological data and revised the manuscript. PDJ was involved in collecting clinical data and revised the manuscript. ENJ participated in collecting and analysing of histopathological data and revised the manuscript. OM participated in the acquisition and interpretation of clinical data and revised the manuscript. MD participated in collecting and analysing of clinical and imaging data and revised the manuscript. MB participated in collecting and interpretation of clinical data and revised the manuscript. JMS participated in the acquisition and interpretation of histopathological data and revised the manuscript. MV participated in collecting and analysing of clinical and histopathological data and revised the manuscript. JBS participated in the acquisition and interpretation of clinical data and revised the manuscript. JW participated in the acquisition and interpretation of histopathological data and revised the manuscript. WK carried out the molecular genetic studies and drafted and revised the manuscript. KGC conceived, coordinated and supervised the study, participated in the collection and analysing of the clinical, histopathological, imaging and genetic data, and corrected the manuscript. All authors read and approved the final manuscript.

\section{Acknowledgements}

We are grateful to the personnel of the Institute of Neuropathology and the Department of Neurology at the RWTH Aachen University hospital, Aachen, Germany, for the technical support. We are thankful to Birgit Halliger-Keller of the Department of Human Genetics at the University of Würzburg, Würzburg, Germany, and Phillipp Helbig, for their technical support, as well as to Pauline Lahaut at the Nice University Hospital for her help in collecting patient's data.

\section{Author details}

${ }^{1}$ Department of Neurology, RWTH Aachen University, Aachen, Germany. ${ }^{2}$ Institute of Neuropathology, RWTH Aachen University, Aachen, Germany ${ }^{3}$ Centre de Référence des Maladies Neuromusculaires, Nice Hospital and UMR CNRS6543, Nice University, Nice, France. ${ }^{4}$ Department of Human Genetics, University of Würzburg, Würzburg, Germany. ${ }^{5}$ Department of 
Neurology, Saarland University, Homburg/Saar, Germany. ${ }^{6}$ Department of Neurology, Neuromuscular Center Ruhrgebiet, University Hospital Bergmannsheil, Ruhr-University Bochum, Bochum, Germany. ${ }^{7}$ Department of Neurology, Klinikum Kassel, Kassel, Germany. ${ }^{8}$ Department of Neurology, Klinikum Merzig, Merzig, Germany. ${ }^{9}$ Department of Neurology, Neuromuscular Reference Center, University Hospital Saint-Luc, Brussel, Belgium. ${ }^{10}$ Institute Born-Bunge, University of Antwerpen, Antwerpen, Belgium. ${ }^{11}$ Neurogenetics Group, VIB-Department of Molecular Genetics, University of Antwerpen, Antwerpen, Belgium. ${ }^{12}$ Department of Neurology, University Hospital of Antwerpen, Antwerpen, Belgium. ${ }^{13}$ Institute of Neuropathology, Heinrich-Heine-University Düsseldorf, Düsseldorf, Germany. ${ }^{14}$ Department of Cardiology, Angiology and Pneumology, University Hospital Heidelberg, Heidelberg, Germany. ${ }^{15}$ DZHK (German Centre for Cardiovascular Research), partner site Heidelberg, Heidelberg, Germany. ${ }^{16}$ Department of Neurology, Martin-Luther-University Halle-Wittenberg, Halle, Germany. ${ }^{17}$ Institute of Neuropathology, Klinikum Bremen-Mitte, Bremen, Germany.

${ }^{18}$ JARA - Translational Brain Medicine, Jülich and Aachen, Germany.

\section{Received: 26 March 2014 Accepted: 21 July 2014}

Published: 1 August 2014

\section{References}

1. De Bleecker JL, Engel AG, Ertl BB: Myofibrillar myopathy with abnormal foci of desmin positivity. II. Immunocytochemical analysis reveals accumulation of multiple other proteins. J Neuropathol Exp Neurol 1996, 55:563-577.

2. Nakano S, Engel AG, Waclawik AJ, Emslie-Smith AM, Busis NA: Myofibrillar myopathy with abnormal foci of desmin positivity. I. Light and electron microscopy analysis of 10 cases. J Neuropathol Exp Neurol 1996, 55:549-562.

3. Selcen D, Ohno K, Engel AG: Myofibrillar myopathy: clinical, morphological and genetic studies in 63 patients. Brain 2004, 127:439-451.

4. Olive M, Goldfarb LG, Shatunov A, Fischer D, Ferrer I: Myotilinopathy: refining the clinical and myopathological phenotype. Brain 2005, 128:2315-2326.

5. Schroder R, Vrabie A, Goebel HH: Primary desminopathies. I Cell Mol Med 2007, 11:416-426.

6. Claeys KG, van der Ven PF, Behin A, Stojkovic T, Eymard B, Dubourg O, Laforet P, Faulkner G, Richard P, Vicart P, Romero NB, Stoltenburg G, Udd B, Fardeau M, Voit T, Furst DO: Differential involvement of sarcomeric proteins in myofibrillar myopathies: a morphological and immunohistochemical study. Acta Neuropathol 2009, 117:293-307.

7. Claeys KG, Fardeau M, Schroder R, Suominen T, Tolksdorf K, Behin A, Dubourg O, Eymard B, Maisonobe T, Stojkovic T, Faulkner G, Richard P, Vicart P, Udd B, Voit T, Stoltenburg G: Electron microscopy in myofibrillar myopathies reveals clues to the mutated gene. Neuromuscul Disord 2008, 18:656-666.

8. Goldfarb LG, Park KY, Cervenakova L, Gorokhova S, Lee HS, Vasconcelos O, Nagle JW, Semino-Mora C, Sivakumar K, Dalakas MC: Missense mutations in desmin associated with familial cardiac and skeletal myopathy. Nat Genet 1998, 19:402-403.

9. Vicart P, Caron A, Guicheney P, Li Z, Prevost MC, Faure A, Chateau D, Chapon F, Tome F, Dupret JM, Paulin D, Fardeau M: A missense mutation in the alphaB-crystallin chaperone gene causes a desmin-related myopathy. Nat Genet 1998, 20:92-95.

10. Selcen D, Engel AG: Mutations in myotilin cause myofibrillar myopathy. Neurology 2004, 62:1363-1371.

11. Vorgerd M, van der Ven PF, Bruchertseifer V, Lowe T, Kley RA, Schroder R Lochmuller H, Himmel M, Koehler K, Furst DO, Huebner A: A mutation in the dimerization domain of filamin c causes a novel type of autosomal dominant myofibrillar myopathy. Am J Hum Genet 2005, 77:297-304.

12. Selcen D, Engel AG: Mutations in ZASP define a novel form of muscular dystrophy in humans. Ann Neurol 2005, 57:269-276.

13. Selcen D, Bromberg MB, Chin SS, Engel AG: Reducing bodies and myofibrillar myopathy features in FHL1 muscular dystrophy. Neurology 2011, 77:1951-1959.

14. Selcen D, Muntoni F, Burton BK, Pegoraro E, Sewry C, Bite AV, Engel AG: Mutation in BAG3 causes severe dominant childhood muscular dystrophy. Ann Neurol 2009, 65:83-89.
15. Sato T, Hayashi YK, Oya Y, Kondo T, Sugie K, Kaneda D, Houzen H, Yabe I, Sasaki H, Noguchi S, Nonaka I, Osawa M, Nishino I: DNAJB6 myopathy in an Asian cohort and cytoplasmic/nuclear inclusions. Neuromuscul Disord 2013, 23:269-276

16. Ohlsson M, Hedberg C, Bradvik B, Lindberg C, Tajsharghi H, Danielsson O, Melberg A, Udd B, Martinsson T, Oldfors A: Hereditary myopathy with early respiratory failure associated with a mutation in A-band titin. Brain 2012, 135:1682-1694.

17. Schroder R, Schoser B: Myofibrillar myopathies: a clinical and myopathological guide. Brain Pathol 2009, 19:483-492.

18. Olive M, Odgerel Z, Martinez A, Poza JJ, Bragado FG, Zabalza RJ, Jerico I, Gonzalez-Mera L, Shatunov A, Lee HS, Armstrong J, Maravi E, Arroyo MR, Pascual-Calvet J, Navarro C, Paradas C, Huerta M, Marquez F, Rivas EG, Pou A, Ferrer I, Goldfarb LG: Clinical and myopathological evaluation of earlyand late-onset subtypes of myofibrillar myopathy. Neuromuscul Disord 2011, 21:533-542.

19. Forrest KM, Al-Sarraj S, Sewry C, Buk S, Tan SV, Pitt M, Durward A, McDougall M, Irving M, Hanna MG, Matthews E, Sarkozy A, Hudson J, Barresi R, Bushby $\mathrm{K}$, Jungbluth $\mathrm{H}$, Wraige E: Infantile onset myofibrillar myopathy due to recessive CRYAB mutations. Neuromuscul Disord 2011, 21:37-40.

20. McLaughlin HM, Kelly MA, Hawley PP, Darras BT, Funke B, Picker J: Compound heterozygosity of predicted loss-of-function DES variants in a family with recessive desminopathy. BMC Med Genet 2013, 14:68.

21. Claeys KG, Fardeau M: Myofibrillar myopathies. Handb Clin Neurol 2013, 113:1337-1342.

22. Olive M, Goldfarb L, Moreno D, Laforet E, Dagvadorj A, Sambuughin N, Martinez-Matos JA, Martinez F, Alio J, Farrero E, Vicart P, Ferrer I: Desminrelated myopathy: clinical, electrophysiological, radiological, neuropathological and genetic studies. J Neurol Sci 2004, 219:125-137.

23. Gamez J, Armstrong J, Shatunov A, Selva-O'Callaghan A, Dominguez-Oronoz R, Ortega A, Goldfarb L, Ferrer I, Olive M: Generalized muscle pseudohypertrophy and stiffness associated with the myotilin Ser55Phe mutation: a novel myotilinopathy phenotype? J Neurol Sci 2009, 277:167-171.

24. Vattemi G, Neri M, Piffer S, Vicart P, Gualandi F, Marini M, Guglielmi V, Filosto $M$, Tonin P, Ferlini A, Tomelleri G: Clinical, morphological and genetic studies in a cohort of 21 patients with myofibrillar myopathy. Acta Myol 2011, 30:121-126.

25. Palmio J, Penttila S, Huovinen S, Haapasalo H, Udd B: An unusual phenotype of late-onset desminopathy. Neuromuscul Disord 2013, 23:922-923.

26. Pfeffer G, Barresi R, Wilson IJ, Hardy SA, Griffin H, Hudson J, Elliott HR, Ramesh AV, Radunovic A, Winer JB, Vaidya S, Raman A, Busby M, Farrugia ME, Ming A, Everett C, Emsley HC, Horvath R, Straub V, Bushby K, Lochmuller H, Chinnery PF, Sarkozy A: Titin founder mutation is a common cause of myofibrillar myopathy with early respiratory failure. J Neurol Neurosurg Psychiatry 2014, 85:331-338.

27. Dagvadorj A, Olive M, Urtizberea JA, Halle M, Shatunov A, Bonnemann C Park KY, Goebel HH, Ferrer I, Vicart P, Dalakas MC, Goldfarb LG: A series of West European patients with severe cardiac and skeletal myopathy associated with a de novo R406W mutation in desmin. J Neurol 2004, 251:143-149.

28. Selcen D, Engel AG: Myofibrillar myopathy caused by novel dominant negative alpha B-crystallin mutations. Ann Neurol 2003, 54:804-810.

29. Walter MC, Reilich P, Huebner A, Fischer D, Schroder R, Vorgerd M, Kress W, Born C, Schoser BG, Krause KH, Klutzny U, Bulst S, Frey JR, Lochmuller H: Scapuloperoneal syndrome type Kaeser and a wide phenotypic spectrum of adult-onset, dominant myopathies are associated with the desmin mutation R350P. Brain 2007, 130:1485-1496.

30. Kley RA, Hellenbroich Y, van der Ven PF, Furst DO, Huebner A, Bruchertseifer V, Peters SA, Heyer CM, Kirschner J, Schroder R, Fischer D, Muller K, Tolksdorf K, Eger K, Germing A, Brodherr T, Reum C, Walter MC, Lochmuller H, Ketelsen UP, Vorgerd M: Clinical and morphological phenotype of the filamin myopathy: a study of 31 German patients. Brain 2007, 130:3250-3264.

31. Sacconi S, Feasson L, Antoine JC, Pecheux C, Bernard R, Cobo AM, Casarin A, Salviati L, Desnuelle C, Urtizberea A: A novel CRYAB mutation resulting in multisystemic disease. Neuromuscul Disord 2012, 22:66-72.

32. Pruszczyk P, Kostera-Pruszczyk A, Shatunov A, Goudeau B, Draminska A, Takeda K, Sambuughin N, Vicart P, Strelkov SV, Goldfarb LG, Kaminska A: Restrictive cardiomyopathy with atrioventricular conduction block resulting from a desmin mutation. Int J Cardiol 2007, 117:244-253. 
33. Olive M, Armstrong J, Miralles F, Pou A, Fardeau M, Gonzalez L, Martinez F, Fischer D, Martinez Matos JA, Shatunov A, Goldfarb L, Ferrer I: Phenotypic patterns of desminopathy associated with three novel mutations in the desmin gene. Neuromuscul Disord 2007, 17:443-450.

34. Yuri T, Miki K, Tsukamoto R, Shinde A, Kusaka H, Tsubura A: Autopsy case of desminopathy involving skeletal and cardiac muscle. Pathol Int 2007, 57:32-36.

35. Strach K, Sommer T, Grohe C, Meyer C, Fischer D, Walter MC, Vorgerd M, Reilich P, Bar H, Reimann J, Reuner U, Germing A, Goebel HH, Lochmuller H, Wintersperger B, Schroder R: Clinical, genetic, and cardiac magnetic resonance imaging findings in primary desminopathies. Neuromuscul Disord 2008, 18:475-482.

36. Odgerel Z, Sarkozy A, Lee HS, McKenna C, Rankin J, Straub V, Lochmuller H, Paola F, D'Amico A, Bertini E, Bushby K, Goldfarb LG: Inheritance patterns and phenotypic features of myofibrillar myopathy associated with a BAG3 mutation. Neuromuscul Disord 2010, 20:438-442.

37. Hong D, Wang Z, Zhang W, Xi J, Lu J, Luan X, Yuan Y: A series of Chinese patients with desminopathy associated with six novel and one reported mutations in the desmin gene. Neuropathol Appl Neurobiol 2011, 37:257-270

38. Hedberg C, Melberg A, Kuhl A, Jenne D, Oldfors A: Autosomal dominant myofibrillar myopathy with arrhythmogenic right ventricular cardiomyopathy 7 is caused by a DES mutation. Eur J Hum Genet 2012, 20:984-985.

39. Ariza A, Coll J, Fernandez-Figueras MT, Lopez MD, Mate JL, Garcia O, Fernandez-Vasalo A, Navas-Palacios JJ: Desmin myopathy: a multisystem disorder involving skeletal, cardiac, and smooth muscle. Hum Pathol 1995, 26:1032-1037.

40. Munoz-Marmol AM, Strasser $G$, Isamat M, Coulombe PA, Yang $Y$, Roca $X$, Vela E, Mate JL, Coll J, Fernandez-Figueras MT, Navas-Palacios JJ, Ariza A, Fuchs E: A dysfunctional desmin mutation in a patient with severe generalized myopathy. Proc Natl Acad Sci U S A 1998, 95:11312-11317.

41. Pinol-Ripoll G, Shatunov A, Cabello A, Larrode P, de la Puerta I, Pelegrin J, Ramos FJ, Olive M, Goldfarb LG: Severe infantile-onset cardiomyopathy associated with a homozygous deletion in desmin. Neuromuscul Disord 2009, 19:418-422.

42. Luan $X$, Hong D, Zhang W, Wang Z, Yuan Y: A novel heterozygous deletion-insertion mutation (2695-2712 del/GTTGT ins) in exon 18 of the filamin $\mathrm{C}$ gene causes filaminopathy in a large Chinese family. Neuromuscul Disord 2010, 20:390-396.

43. Dalakas MC, Dagvadorj A, Goudeau B, Park KY, Takeda K, Simon-Casteras M, Vasconcelos O, Sambuughin N, Shatunov A, Nagle JW, Sivakumar K, Vicart P, Goldfarb LG: Progressive skeletal myopathy, a phenotypic variant of desmin myopathy associated with desmin mutations. Neuromuscul Disord 2003, 13:252-258.

44. Henderson M, De Waele L, Hudson J, Eagle M, Sewry C, Marsh J, Charlton R, He L, Blakely EL, Horrocks I, Stewart W, Taylor RW, Longman C, Bushby K, Barresi R: Recessive desmin-null muscular dystrophy with central nuclei and mitochondrial abnormalities. Acta Neuropathol 2013, 125:917-919.

45. Izumi R, Niihori T, Aoki Y, Suzuki N, Kato M, Warita H, Takahashi T, Tateyama M, Nagashima T, Funayama R, Abe K, Nakayama K, Aoki M, Matsubara Y: Exome sequencing identifies a novel TTN mutation in a family with hereditary myopathy with early respiratory failure. J Hum Genet 2013, 58:259-266.

46. Jaffer F, Murphy SM, Scoto M, Healy E, Rossor AM, Brandner S, Phadke R, Selcen D, Jungbluth $\mathrm{H}$, Muntoni F, Reilly MM: BAG3 mutations: another cause of giant axonal neuropathy. J Peripher Nerv Syst 2012, 17:210-216.

47. Reilich P, Schoser B, Schramm N, Krause S, Schessl J, Kress W, Muller-Hocke J, Walter MC, Lochmuller H: The p.G154S mutation of the alpha-B crystallin gene (CRYAB) causes late-onset distal myopathy. Neuromuscul Disord 2010, 20:255-259.

48. Lee HC, Cherk SW, Chan SK, Wong S, Tong TW, Ho WS, Chan AY, Lee KC, Mak CM: BAG3-related myofibrillar myopathy in a Chinese family. Clin Genet 2012, 81:394-398.

49. Kraya T, Kress W, Stoevesant D, Deschauer M, Zierz S: [Myofibrillary myopathy due to the ZASP mutation Ala147Thr: two cases with exclusively distal leg involvement]. Nervenarzt 2013, 84:209-213.

50. Hanisch F, Kraya T, Kornhuber M, Zierz S: Diagnostic impact of myotonic discharges in myofibrillar myopathies. Muscle Nerve 2013, 47:845-848.

51. Fischer D, Kley RA, Strach K, Meyer C, Sommer T, Eger K, Rolfs A, Meyer W, Pou A, Pradas J, Heyer CM, Grossmann A, Huebner A, Kress W, Reimann J,
Schroder R, Eymard B, Fardeau M, Udd B, Goldfarb L, Vorgerd M, Olive M: Distinct muscle imaging patterns in myofibrillar myopathies. Neurology 2008, 71:758-765.

52. Wattjes MP, Kley RA, Fischer D: Neuromuscular imaging in inherited muscle diseases. Eur Radiol 2010, 20:2447-2460.

53. Joshi PR, Hauburger A, Kley R, Claeys KG, Schneider I, Kress W, Stoltenburg G, Weis J, Vorgerd M, Deschauer M, Hanisch F: Mitochondrial abnormalities in myofibrillar myopathies. Clin Neuropathol 2014, 33:134-142.

54. Dubowitz V, Sewry C: Muscle biopsy a practical approach. 3rd edition Philadelphia: Elsevier; 2007

55. Weis J, Brandner S, Lammens M, Sommer C, Vallat JM: Processing of nerve biopsies: a practical guide for neuropathologists. Clin Neuropathol 2012, 31:7-23.

56. Sanger F, Air GM, Barrell BG, Brown NL, Coulson AR, Fiddes CA, Hutchison CA, Slocombe PM, Smith M: Nucleotide sequence of bacteriophage phi X174 DNA. Nature 1977, 265:687-695.

57. Vasli N, Laporte J: Impacts of massively parallel sequencing for genetic diagnosis of neuromuscular disorders. Acta Neuropathol 2013, 125:173-185.

58. Sato T, Hayashi YK, Keduka E, Noguchi S, Osawa M, Nonaka I, Nishino I: Novel BAG3 mutations in myofibrillar myopathy patients [abstract]. Neuromuscul Disord 2011, 21:740

59. Wahbi K, Behin A, Charron P, Dunand M, Richard P, Meune C, Vicart P, Laforet P, Stojkovic T, Becane HM, Kuntzer T, Duboc D: High cardiovascular morbidity and mortality in myofibrillar myopathies due to DES gene mutations: a 10-year longitudinal study. Neuromuscul Disord 2012, 22:211-218.

60. Kley RA, Serdaroglu-Oflazer P, Leber Y, Odgerel Z, van der Ven PF, Olive M, Ferrer I, Onipe A, Mihaylov M, Bilbao JM, Lee HS, Hohfeld J, Djinovic-Carugo K, Kong K, Tegenthoff M, Peters SA, Stenzel W, Vorgerd M, Goldfarb LG, Furst DO: Pathophysiology of protein aggregation and extended phenotyping in filaminopathy. Brain 2012, 135:2642-2660.

61. Pilotto A, Marziliano N, Pasotti M, Grasso M, Costante AM, Arbustini E: alphaB-crystallin mutation in dilated cardiomyopathies: low prevalence in a consecutive series of 200 unrelated probands. Biochem Biophys Res Commun 2006, 346:1115-1117.

\section{doi:10.1186/s13023-014-0121-9}

Cite this article as: Semmler et al.: Unusual multisystemic involvement and a novel BAG3 mutation revealed by NGS screening in a large cohort of myofibrillar myopathies. Orphanet Journal of Rare Diseases 2014 9:121.

\section{Submit your next manuscript to BioMed Central and take full advantage of:}

- Convenient online submission

- Thorough peer review

- No space constraints or color figure charges

- Immediate publication on acceptance

- Inclusion in PubMed, CAS, Scopus and Google Scholar

- Research which is freely available for redistribution 